\title{
Reply to Editorial
}

\author{
"Do You See Yonder Cloud?"-On Priming Concepts, A New Test and a Familiar Outcome. \\ Reply to Lucas et al.: "Familiarity or Conceptual Priming? Good Question! Comment \\ on Stenberg, Hellman, Johansson, and Rosén (Previous Issue)"
}

\section{Georg Stenberg, Mikael Johansson, Johan Hellman, and Ingmar Rosén}

\begin{abstract}
Lucas, Voss, and Paller (issue no. 3) sympathize with our intentions but disagree with our findings. They argue that a relation between frequency and conceptual priming may have been obscured by methodological details in our second experiment, therefore failing to complete a bridge between conceptual priming and FN400 with name frequency as the mediator. How-
\end{abstract}

Despite the vast number of ERP studies of recognition memory, there have been only a few studies demonstrating a double dissociation of the putative ERP correlates of recollection and familiarity within an experiment (Jäger, Mecklinger, \& Kipp, 2006; Woodruff, Hayama, \& Rugg, 2006). Our recent article (Stenberg, Hellman, Johansson, \& Rosén, in press) joins those findings by showing that orthogonal manipulations of frequency and fame selectively influence contributions of familiarity (FN400 old/new effect) and recollection (left parietal old/new effect) to recognition memory for names. Strong support for dual-process accounts of recognition memory can be derived from these data. We further argued that our data can inform interpretations of the FN400 old/new effect, a currently debated issue.

In a second behavioral experiment, fame and not frequency influenced measures of conceptual priming. Given the strong relationship between the frequency and the FN400 old/new effect, we concluded that this early old/ new effect seemed to index familiarity (cf. Rugg \& Curran, 2007) rather than conceptual priming (cf. Paller, Voss, \& Boehm, 2007). Although Lucas, Voss, and Paller (in press) profess sympathy for our attempts to disentangle familiarity and conceptual priming, they take issue with our conclusions, against which they present three main points of criticism. They argue that a relation between frequency and conceptual priming (a) may have been overlooked in our analysis and (b) was not given a fair chance to develop. Further, they argue that (c) the relation between frequency and familiarity, which we did find, was not the one that the familiarity hypothesis predicted.

\section{SENSITIVITY OF THE CONCEPTUAL PRIMING MEASURE}

Lucas et al. (in press) argue that an analysis of a subset of the data from Experiment 2, that is, the fame decision ever, renewed inspections of our experiment and a new additional experiment, designed to meet the objections, fail to find any role for name frequency in conceptual priming and therefore reestablish the dissociation of priming and the FN400. On closer inspection, our differing views seem to derive from different interpretations of the term "concept."

task, would provide a more sensitive test of an effect of frequency on conceptual priming. We ran the requested analysis and failed anew to find any reliable influence of frequency, $F(1,12)=1.98, n s$. In terms of effect sizes, the effect of fame was five times stronger than that of frequency. To support their position, Lucas et al. would have to explain not only that frequency, while producing the FN400, failed to give conceptual priming but also that fame, while giving rise to much stronger conceptual priming, failed to produce the FN400.

\section{COMPARABILITY OF CONCEPTUAL PROCESSING ACROSS EXPERIMENTS}

Lucas et al. (in press) note that the encoding tasks were different and suggest that the intentional encoding in Experiment 1 served to enhance conceptual fluency for infrequent names and incidental encoding, with a frequency-decision orienting task, in one condition of Experiment 2, favored famous names. From their comments, it remains unclear why a frequency-decision task should prime famous names selectively and not frequent/infrequent names. Wouldn't it be much simpler to assume, as we do, that the fame dimension makes a real difference for conceptual priming because people have concepts associated with famous people, and concepts are invariably found at the business end of conceptual priming? Frequency, on the other hand, does not make a difference because rare, unheard of, even outlandishly quaint names do not carry conceptual content. They may trigger a stray, idiosyncratic association, yes, and in this diluted sense they may prime something, but for substantial priming to take place the association will have to be reliably repeated.

Even if one were to accept the assumptions of Lucas et al. (in press) regarding conceptual processing for minimally meaningful stimuli and, for the sake of argument, 


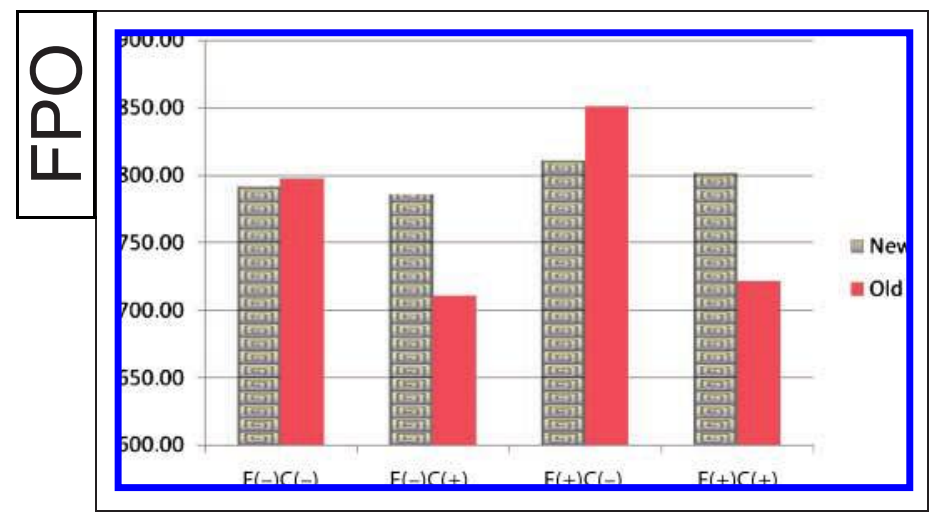

Figure 1. RTs and error rates for the old and new names in the priming task. Name types are formed by the independent combination of frequency and celebrity in high $(+)$ or low $(-)$ degrees. Note that reactions to famous names grow both faster and more accurate as they are primed. Note also that rare, nonfamous names, that is, the category for which the FN400 effect was largest, show no priming at all. Note also that the phenomenon of "false fame"-falsely designating as famous a name that has been recently primed-applies to some extent to common, nonfamous names but not to rare, nonfamous names. Therefore, the lack of RT priming for this group cannot be ascribed to hesitancy and equivocation caused by false

concede that such processing occurred for rare names in Experiment 1, a lot of explaining would still remain to be done. If nonfamous names could release such conceptual processing, how much more wouldn't we expect from famous names? The requirements for conceptual processing are fulfilled, a host of facts are known about these persons that can be summoned up at will. The stage would be set for substantial, reliably repeated conceptual processing, which, according to the view of Lucas et al., should be accompanied by a large FN400 effect. Yet, we see none; why?

On one point, we grant that Lucas et al. (in press) have pinpointed a shortcoming in our study. The encoding conditions in the two experiments were not identical, and through this loophole, noise may have entered. Because it is not possible to argue about this possibility by armchair theorizing alone, we ran a follow-up behavioral conceptual priming study to amend and assess the consequences.

The experiment, comprising 24 participants, used study instructions identical to those in Experiment 1 (i.e., "remember as much as you can") and a test phase identical to the speeded fame judgment in Experiment 2. Thus, the conditions implemented the very conjunction of encoding task and priming measurement, to which Lucas et al. (in press) appealed. With a type of encoding that gives free rein to idiosyncratic associations, opportunities are maximal for the kind of processing that is included in the generous definition of conceptual priming (Paller et al., 2007). With a priming task that has a proven track record (Experiment 2), measurement should be sensitive enough to detect all possible traces of conceptual priming associated with frequency. We ran the experiment (with Inquisit, on the Internet, just as Experiment 2), and the results are as follows:

The effect of celebrity on RT priming scores (new minus old) was highly reliable, $F(1,23)=57.36, p<.001$, and the effect size (partial $\eta^{2}$ ) was large (0.71). The effect of frequency, on the other hand, was nonsignificant $F(1,23)=$ $1.36, p>.25$, and negligible, $\eta^{2}=0.06$. There was no interaction (Figures 1 and 2).

In all relevant aspects, this follow-up experiment reproduced the outcome of Experiment 2. Fame sustained priming, and frequency did not. Thus, our efforts to disclose any hitherto hidden links between frequency and conceptual priming, and by extension any link between conceptual priming and the FN400, failed even under these favorable conditions. The encoding condition was the one designated by Lucas et al. (in press) as likely to promote conceptual processing for all names, whether famous or not.

\section{FINDINGS "CONTRADICT AN ASSOCIATION BETWEEN FN400 AND FAMILIARITY"}

Lucas et al. (in press) argue that our findings of a strong coupling of FN400 old/new effect and rare names contradict an association between this ERP effect and familiarity. By this they mean that high-frequency names should be expected to be familiar and therefore produce an FN400 effect, which they did not. After all, what could be more familiar than names such as Smith and Jones? True, but not quite to the point.

As we argue in the article, quoting Mandler's (1980) seminal work, it is the familiarity increment that counts, that is, the increase a studied object incurs, going from its

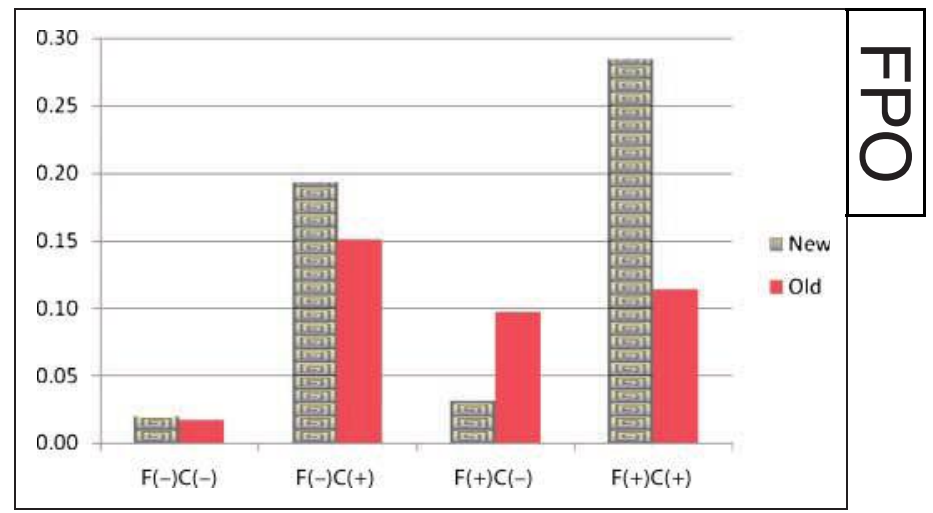

Figure 2. RTs and error rates for the old and new names in the priming task. Name types are formed by the independent combination of frequency and celebrity in high $(+)$ or low $(-)$ degrees. Note that reactions to famous names grow both faster and more accurate as they are primed. Note also that rare, nonfamous names, that is, the category for which the FN400 effect was largest, show no priming at all. Note also that the phenomenon of "false fame"-falsely designating as famous a name that has been recently primed-applies to some extent to common, nonfamous names but not to rare, nonfamous names. Therefore, the lack of RT priming for this group cannot be ascribed to hesitancy and equivocation caused by false fame. 
resting level to a freshly activated state. This step can be huge for a rare and odd name; for a common name, it may be negligible. In addition, as predicted by this hypothesis, familiarity in the recognition test was indeed much higher for rare names than for common names. Common names had clearly lower familiarity estimates in the behavioral data (see dp values in Table 1) than rare names did. Lucas et al. (in press) insist that common names evoked "high levels of familiarity." If they are referring to an absolute benchmark level above which a dp value may be called high, then this gold standard is unknown to us.

For us, it suffices to note that common names had lower familiarity estimates than rare names. They also had lower FN400 effects, both facts being fully compatible with the familiarity increment hypothesis.

Summing it all up, we have taken to heart the injunction of Lucas et al. (in press) to search for FN400 antecedents in conceptual priming. We have looked high and low, but we did not find any. What set off this chase was an exceedingly generous interpretation of the "conceptual" part in conceptual priming. If "concepts" can be any arbitrary association that comes to a mind when confronted with a stimulus, then the term becomes subjective, unverifiable, and arbitrary. Yet that is the sense of the word advocated by Lucas et al.: "stimuli that are seemingly devoid of meaning can nonetheless be perceived as meaningful, much as a cloud might be seen to resemble an animal." A cloud can indeed be seen as almost anything, as shown by Hamlet (1603). Speaking to the courtier Polonius, he enumerates a succession of possibilities:

Hamlet: "Do you see yonder cloud that's almost in shape of a camel?.. Methinks it is like a weasel... Or like a whale?"

Polonius, always the diplomat, finds it necessary to follow the prince in every whim. But what is really being primed here, apart from the big, white, fluffy thing that is being perceptually primed? Camel, weasel, whale, or all of the above? Is there a way of knowing? We hope that there is, by sticking to the original meaning of the term concept, giving to "airy nothing a local habitation and a name."

\section{Georg Stenberg}

georg.stenberg@gmail.com

Mikael Johansson

mikael.johansson@psychology.lu.se

Johan Hellman

johan.hellman@psychology.lu.se

Ingmar Rosén

ingmar.rosen@telia.com

\section{REFERENCES}

Jäger, T., Mecklinger, A., \& Kipp, K. (2006). Intra- and inter-item associations doubly dissociate the electrophysiological correlates of familiarity and recollection. Neuron, 52, 535-545.

Lucas, H., Voss, J. L., \& Paller, K. A. (in press). Familiarity or conceptual priming? Good question! Comment on Stenberg, Hellman, Johansson, and Rosén. Journal of Cognitive Neuroscience.

Mandler, G. (1980). Recognizing: The judgment of previous occurrence. Psvchological Review, 87, 252-271.

Paller, K. A., Voss, J. L., \& Boehm, S. G. (2007). Validating neural correlates of familiarity. Trends in Cognitive Sciences, 11, 243-250.

Rugg, M. D., \& Curran, T. (2007). Event-related potentials and recognition memory. Trends in Cognitive Sciences, 11, 251-257.

Stenberg, G., Hellman, J., Johansson, M., \& Rosén, I. (in press). Familiarity or conceptual priming: Event-related potentials in name recognition. Journal of Cognitive Neuroscience.

Woodruff, C. C., Hayama, H. R., \& Rugg, M. D. (2006). Electrophysiological dissociation of the neural correlates of recollection and familiarity. Brain Research, 1100, $125-135$. 